\title{
A Novel Analysis Method for Lactate Dehydrogenase Activity in Serum Samples Based on Fluorescence Capillary Analysis
}

\author{
Qiao-Jing LI, ${ }^{*}$ Yong-Sheng LI, ${ }^{* \dagger}$ and Xiu-Feng GAO**† \\ *School of Chemical Engineering, Sichuan University, Chengdu 610065, P. R. China \\ **West China School of Preclinical and Forensic Medicine, Sichuan University, Chengdu 610041, P. R. China
}

\begin{abstract}
Based on fluorescence capillary analysis technology, a method for quantitating lactate dehydrogenase (LDH) activity in a micro-volume sample was developed. Sample and reagent consumptions were merely 2 and $16 \mu \mathrm{L}$ per time, respectively. The optimized test conditions were as follows. The reaction reagent consisted of $0.10 \mathrm{M}$ phosphate buffer (pH 6.5), $0.30 \mathrm{mM}$ NADH and $1.20 \mathrm{mM}$ pyruvate. NADH standard was prepared with a phosphate buffer of $\mathrm{pH}$ 8.0, and its linear response was controlled in $0.05-0.30 \mathrm{mM}$. LDH standards containing $2.0 \mathrm{mM}$ PEG could exhibit long-term stability. Under the optimized conditions, a linear response for LDH from 50 to $1200 \mathrm{U} \mathrm{L}^{-1}$ and a detection limit of $31 \mathrm{U} \mathrm{L}^{-1}$ were obtained with good precision (RSD: $2.1-2.2 \%, n=10$ ) and better recovery of $96-105 \%$. The method's characteristics was high sensitivity, low consumptions, simple operations, good precision and reliability, lending itself to the miniaturization of fluorophotometer which transformed into a bedside instrument in the hospital.
\end{abstract}

Keywords Fluorescence capillary analysis, immobilized enzyme, biosensor, pyruvate, lactate, lactate dehydrogenase

(Received December 3, 2014; Accepted February 23, 2015; Published May 10, 2015)

\section{Introduction}

The lactate dehydrogenase $(\mathrm{LDH})$ is also called $\mathrm{NAD}^{+}$ oxidoreductase; it plays an important role in cells for energy production. It is a catalyst of mutual conversion between lactate (LA) and pyruvate (PA), and almost exists in any kinds of tissue cells, ${ }^{1}$ if the cells are damaged, any $\mathrm{LDH}$ within them will leak into the plasma, resulting in an increase of the total serum LDH level. Literature results ${ }^{2}$ show that the determination of LDH activity in serum has important clinical significance in the diagnosis of diseases, such as acute myocardial infarction, viral hepatitis, cirrhosis, and pernicious anemia. Therefore, analysts have developed many methods for the quantification of LDH activity.

LDH catalyses this reversible reaction: $\mathrm{LA}+\mathrm{NAD}^{+} \stackrel{\mathrm{LDH}}{\longleftrightarrow}$ $\mathrm{PA}+\mathrm{NADH}+\mathrm{H}^{+}$. When the $\mathrm{pH}$ is between 6.0 and 7.5, the reaction favours the conversion of $\mathrm{PA}$ into $\mathrm{LA}$, and when the $\mathrm{pH}$ is more than 7.5 it favours the conversion of LA into PA. ${ }^{3}$ Nevertheless, both reactions can be used to estimate the LDH activity.

Amperometric biosensors for estimating the LDH activity are more common. Some of them involve measurements of an anodic current due to $\mathrm{H}_{2} \mathrm{O}_{2}$ generated in a second coupled enzymatic reaction, catalyzed by $\mathrm{NADH}$ oxidase, ${ }^{4}$ lactate oxidase or pyruvate oxidase. ${ }^{5}$ Oxygen-consuming sensors have also been reported (linear range: $25-180 \mathrm{U} / \mathrm{L}$ ). ${ }^{6-8}$ Toluidine blue-O (the sample volume $200 \mu \mathrm{L}$; range 50 - $200 \mathrm{U} \mathrm{L}^{-1}$; RSD $3.2 \%),{ }^{9}$ potassium hexacyanoferrate(II), ${ }^{10}$ nickel hexacyano-

$\dagger$ To whom correspondence should be addressed. E-mail: lysgxf2005@qq.com (Y.-S. L.); xiufengg@163.com (X.F. G.) ferrate (the $10-350 \mathrm{kU} / \mathrm{L}$ ), ${ }^{11}$ adenosine diphosphate (sample volume $30 \mu \mathrm{L}$; range $33.3-667 \mathrm{U} \mathrm{L}^{-1}$; detection limit 13.5 $\mathrm{U} \mathrm{L} \mathrm{L}^{-1}$; RSD $\left.5 \%\right)^{12}$ have been used as mediators to determine the $\mathrm{LDH}$ activities.

Additionally, the LDH activity is also routinely measured spectrophotometrically based on the absorbance change $(\Delta A)$ of the cofactor NADH at $340 \mathrm{~nm}$. Photometric determinations of LDH were performed often using two different methods. ${ }^{13,14}$ One method is to allow the LDH activity to be evaluated by monitoring the $\mathrm{NAD}^{+}$absorbance reduction at $340 \mathrm{~nm}$. The change value in the absorbance with time is directly proportional to the $\mathrm{LDH}$ activity when $\mathrm{NAD}^{+}$is converted to NADH. Another method $^{15}$ is a kinetic determination for LDH activity based on the oxidation rate of $\mathrm{NADH}$, in accordance with the following consumption of NADH at $340 \mathrm{~nm}$.

In order to increase the sensitivity of the photometry, some colorimetric assays were developed, in which the detection wavelengths were moved in the visible spectrum area $(500-$ $600 \mathrm{~nm}$ ). The most popular methods were the end-point method $^{16}$ and a kinetic assay ${ }^{17-18}$ based on the reduction of a tetrazolium salt to a formazan dye via diaphorase, or some electron-transfer mediators, such as phenazine methosulphate, ${ }^{19}$ These methods (sample volume $20-100 \mu \mathrm{L}$; range 72 $180 \mathrm{U} \mathrm{L}^{-1}$; $\mathrm{SD} \pm 18 \mathrm{U} \mathrm{L}^{-1}$ ) were three times as sensitive as the corresponding ultraviolet method.

However so far, achievements reported on fluorophotometry for quantifying the LDH activity have very few. One study ${ }^{20}$ once utilized the diffussion diameter of the NADH's fluorescent area to attempt the LDH activity quantification. Another was a rather complicated flow-injection fluorescence system for the on-line detection of the intracellular LDH during fermentation using any fluorescent decrease of NADH (the range $100-$ $\left.5400 \mathrm{U} \mathrm{L}^{-1}\right){ }^{21}$ However, it has not yet been reported yet that a 
common fluorophotometer and fluorescent NADH is directly utilized to determine the $\mathrm{LDH}$ activity.

Although it is clear that the sensitivity of spectrofluorimetry is much higher than that of UV-vis spectrophotometry, the latter are more frequently adopted in routine analyses. This is because the price of one fluorophotometer was more expensive than that of one UV-vis spectrophotometer. But along with the rapid development of science and economy, the price difference of two sorts of instruments will change to be smaller, and so the fluorophotometer will become increasingly popular for assays. Besides, when analysis method itself belongs to low-sensitivity, this means that every time assay will consume more test samples and reagents (at least $10 \mathrm{~mL}$ for a time), which will result in excessive waste and environmental pollution.

Accordingly, in the present work we have made great efforts to decrease the reagent dosage under an ensuring premise of the height sensitivity fluorophotomety, using a common fluorophotometer. We utilized a medical glass capillary to substitute a 4-mL expensive quartz cell, and achieved an obvious decrease in the reagent consumption and test costs. Fluorescent capillary analysis technology (FCA) ${ }^{22}$ was also born under this idea. In FCA, the capillary is not only a sample container, but also may be a reactor, catalysts and probes, and even reagents may be immobilized on the capillary's inner-wall to realize a repetitive utilization of them, multi-objective application, or to develop some disposable analytical kit. This method is very suitable for precious and less samples (or reagents) to assay. Based on the FCA, some new determination method has been published for micro-volume alcohol, ${ }^{23}$ DNA, ${ }^{24}$ lactic acid, ${ }^{25}$ pyruvate, ${ }^{26}$ trace-level sulfated bile acid in urine ${ }^{27}$ and blood glucose, ${ }^{28}$ however, the feasibility of using the FCA method to quantify enzyme activity in a micro-volume sample is still not confirmed. Therefore, we carried out this research in which the LDH activity was determined by the FCA method based on fluorescent NADH $\left(\lambda_{\mathrm{ex}} / \lambda_{\mathrm{em}} 350 \mathrm{~nm} / 460 \mathrm{~nm}\right)$ to non-fluorescent $\mathrm{NAD}^{+}$.

\section{Experimental}

\section{Materials and apparatus}

The following enzymes and chemicals were used: LDH stock solution (EC 1.1.1.27, $9951 \mathrm{kU} \mathrm{L}^{-1}, \mathrm{pH} 7.5$ at $37^{\circ} \mathrm{C}$ ) purchased from Amersco (Solon, $\mathrm{OH}$ ), $\mathrm{NADH}$, sodium pyruvate and polyethylene glycol (PEG, $6000 \mathrm{~g} \mathrm{~mol}^{-1}$ ) purchased from Sanland (Amoy, China). LDH assay kits (IFCC method) were from Wako Pure Chemical Industries, Ltd. (Osaka, Japan).

All fluorescence measurements were made with an RF5301PC fluorophotometer from Shimadzu Co. (Tokyo, Japan). A capillary holder mounted on the fluorophotometer was selfmade. A glass capillary (i.d. $0.7 \mathrm{~mm}$; o.d. $1.4 \mathrm{~mm}$ ) was purchased from Drummond Scientific Co. (Broomall, PA). The capillaries were washed with phosphate buffer before use. All mass measurements were performed using an AUW120D electronic balance from Shimadzu Co. (Tokyo, Japan). The PHscan10-type digital $\mathrm{pH}$ meter used in all acidity measurements was purchased from Bante Instrument Co. (Shanghai, China).

\section{Preparation of reagent solutions}

3.0 mM NADH solution: $11.46 \mathrm{mg}$ of NADH was dissolved and diluted to $5.0 \mathrm{~mL}$ using a $0.05 \mathrm{M}$ phosphate buffer ( $\mathrm{pH} 8.0$ ). The buffer was freshly prepared daily, and should be used within $12 \mathrm{~h}$.

$20 \mathrm{mM}$ PEG solution: $1.20 \mathrm{~g}$ of PEG was dissolved and diluted to $10.0 \mathrm{~mL}$ with ultra-purified water.
$1.0 \mathrm{kU} \mathrm{L}^{-1} \mathrm{LDH}$ standard: $0.50 \mu \mathrm{L}$ of a commercial $\mathrm{LDH}$ solution and $500.0 \mu \mathrm{L}$ of the PEG solution were transferred into a 6-mL test tube with a volumetric pipet, and the mixture was diluted to $5.0 \mathrm{~mL}$ of fine volume with phosphate buffer $(0.10 \mathrm{M}$, $\mathrm{pH}$ 6.5).

\section{Self-assembly apparatus for FCA}

The FCA apparatus consisted of a conventional fluorophotometer, a capillary and a capillary-holder, which were inserted into a quartz-cuvette socket. The capillary-holder was composed of the holder body, an inserting channel for the capillary, four excitation-beam/emission-beam windows, and an adjusting screw for regulating the position of the capillary. The inserting channel for the capillary was positioned on the vertical axis of the holder, such that the inserted capillary could be perpendicular to the excitation or emission beams. The excitation-beam and the emission-beam windows could avoid the interferences of stray light and any refracted light from excitation light. The light window width is narrower than the inner diameter of the capillary do as to minimize any reflection of the capillary's outer-wall. Also an adjusting screw on the bottom of the holder was used to regulate the depth of the capillary inserted. In order to keep the imbibed liquid from leaking-out, one end of the capillary was sealed with a rubber cap. The capillaries must be screened prior to use. The purpose was to pick out some capillaries having the same fluorescent blank. After inserting the holder into the socket, the apparatus for the FCA was constituted. Correlative operation parameters for fluorescent detection were set up by means of the fluorophotometer.

Before any analysis, a reaction mixture solution is inhaled beforehand into the capillary by utilizing a capillarity. Its one end is sealed with the rubber cap, and then the capillary is inserted into the capillary holder until contacting the funnelshaped top of the screw. After each measurement, the capillary is removed from the holder, and its bottom is let gently touch absorbent paper (or material making napkin) put in a small box. Any liquid in the capillary will be discharged quickly, and absorbed into the paper. Because this emptied capillary inhales the phosphate buffer to clean once, it can be used for the next determination. If money is available, the capillary can be disposable. When multiple samples must be analyzed, we can also simultaneously use multiple capillaries to suck different reaction mixture solutions and to detection sequence.

\section{Quantitive principle of $\mathrm{LDH}$ activity based on FCA}

The enzyme activity represents the ability of some enzyme catalyzing a biochemical reaction. In suitable acidity, temperature, and substrate concentration, the amount of enzyme for $1.0 \mu \mathrm{M}$ substrate converting to products per minute is designated as a unit of enzyme activity ( 1 Unit, $U=1 \mu \mathrm{mol}$ $\left.\min ^{-1}\right)$. The activity concentration of the enzyme $\left(E_{\mathrm{c}}\right)$ is defined as the enzyme activity per volume of enzyme solution $\left(\mathrm{U} \mathrm{L}^{-1}\right)$. A common assay principle for $\mathrm{LDH}$ activity is: pyruvate $+\mathrm{H}^{+}$ $\stackrel{\mathrm{LDH}}{\longrightarrow}$ lactate $+\mathrm{NAD}^{+}$. Under the catalysis of $\mathrm{LDH}$ at pH 6.0 - 7.5, fluorescent NADH as a substrate reacts with another substrate PA, and turns into a non-fluorescent $\mathrm{NAD}^{+}$. Accompanying the NADH consumption, its fluorescent intensity $(F)$ gradually decreases. During this period, if the NADH $\left(c_{\mathrm{NADH}}\right)$ and $\mathrm{PA}\left(c_{\mathrm{PA}}\right)$ concentrations are excessive, the reaction rate and extent will depend on the activity and the amount of LDH. Therefore, in light of the fluorescent quenching per time unit $(\Delta F / \Delta t)$, the activity concentration of $\mathrm{LDH}\left(E_{\mathrm{C}}^{\mathrm{LDH}}\right)$ can be quantified.

After being derived mathematically, the following formula for 
calculating $E_{\mathrm{C}}^{\mathrm{LDH}}$ was obtained:

$$
\begin{aligned}
& E_{\mathrm{C}}^{\mathrm{LDH}}=v=\frac{\Delta F}{\Delta t} \times \frac{1000}{K_{\mathrm{NADH}}} \times \frac{V}{V_{\mathrm{s}}}, \\
& E_{\mathrm{C}}^{\mathrm{LDH}}=v=\frac{k_{\mathrm{qc}}}{K_{\mathrm{NADH}}} \times \frac{V}{V_{\mathrm{s}}} \times 1000,
\end{aligned}
$$

Here, $E_{\mathrm{C}}^{\mathrm{LDH}}$ can be viewed as being equal to the catalytic reaction

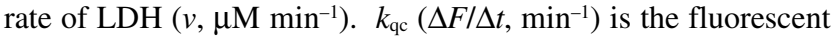
decrement of NADH per minute in the PA/NADH/LDH system; $K_{\mathrm{NADH}}\left(\Delta F / \Delta c_{\mathrm{NADH}}, \mathrm{L} \mathrm{mol}^{-1}\right)$ is a proportional coefficient between

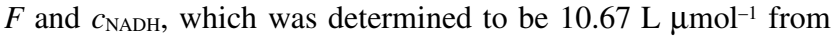
the experiment; $V$ is the total volume of the reaction system $(\mu \mathrm{L}) ; V_{\mathrm{s}}$ is the LDH solution volume added in the reaction system $(\mu \mathrm{L}) . V / V_{\mathrm{s}}$ are 10 in the FCA assay, and represent the dilution ratio of LDH samples. After simplifying Eq. (2), and the following was obtained:

$$
E_{\mathrm{C}}^{\mathrm{LDH}}=v=\frac{k_{\mathrm{qc}}}{K_{\mathrm{NADH}}} \times 10^{4}(\mu \mathrm{M} / \mathrm{min}),
$$

Consequently, we used Eq. (3) to calculate $E_{\mathrm{C}}^{\mathrm{LDH}}$ in the next FCA test.

\section{Operation procedure of the method}

The pass-band widths of excitation $\left(\lambda_{\mathrm{ex}}: 350 \mathrm{~nm}\right)$ and emission beams $\left(\lambda_{\mathrm{em}}: 460 \mathrm{~nm}\right)$ of the fluorophotometer were fixed at 3 and $15 \mathrm{~nm}$ respectively, and the instrument response was set at the high-sensitivity position.

First of all, different $c_{\mathrm{NADH}}$ were imbibed, respectively, in turn into the glass capillary to detect their fluorescent intensity in $0.1-0.3 \mathrm{mM}$. An $F-c_{\mathrm{NADH}}$ curve $\left(F=K_{\mathrm{NADH}} c_{\mathrm{NADH}}\right)$ was drawn, and $K_{\mathrm{NADH}}$ was obtained. Secondly, dynamic fluorescence detection of the reaction mixture was conducted, and a fluorescent quenching curve ( $F-t$ curve) was acquired to find the $\Delta F / \Delta t\left(k_{\mathrm{qc}}\right)$ value by calculations.

The detailed operation procedure was as follows (Fig. 1). After $20-\mu \mathrm{L} 3.0 \mathrm{mM}$ NADH and a $20-\mu \mathrm{L}$ serum sample (or pure $\mathrm{LDH}$ solution) were added into a $0.5-\mathrm{mL}$ vial, it was incubated for $10 \mathrm{~min}$, sequentially $160-\mu \mathrm{L} 1.50 \mathrm{mM}$ PA was added in the vial (this $200 \mu \mathrm{L}$ reaction mixture was enough for 10 tests). Then, the reaction mixture was immediately imbibed into the glass capillary to detect and acquire its dynamic curves on the fluorophotometer and relational $k_{\mathrm{qc}}$. This procedure was repeated three times, and the mean value of $k_{\mathrm{qc}}$ was obtained from the linear interzone of the dynamic curves. Finally, $E_{\mathrm{C}}^{\mathrm{LDH}}$ was found by substituting $k_{\mathrm{qc}}$ and $K_{\mathrm{NADH}}$ into Eq. (3).

In the routine test, for convenience, a two-point method could be adopted for finding $k_{\mathrm{qc}}$. Namely, a time interval $\left(\Delta t=t_{0}-t_{\mathrm{x}}\right)$ is selected within the linear zone of the $F-t$ curve. The fluorescent intensity of a start point $\left(t_{0}\right)$ on the $F-t$ curve is designated as an initial fluorescence value $\left(F_{0}\right)$, and then the fluorescent intensity $\left(F_{\mathrm{t}}\right)$ at some elapsed time $\left(t_{\mathrm{x}}\right)$ is designated as an end fluorescence value $\left(F_{\mathrm{t}}\right)$. The decreased value of the fluorescent intensity $\left(\Delta F=F_{0}-F_{\mathrm{t}}\right)$ is divided by the time interval $(\Delta t)$ to obtain the $\Delta F / \Delta t$, which is the value of $k_{\mathrm{qc}}$.

\section{Results and Discussion}

In order to achieve the best efficiency of the method, we investigated some cases including the LDH solution stability, PEG and $\mathrm{Na}_{2}$ EDTA effects, phosphate buffer concentration, $\mathrm{NADH}$ linear response, $\mathrm{pH}$ of the reaction system, NADH and

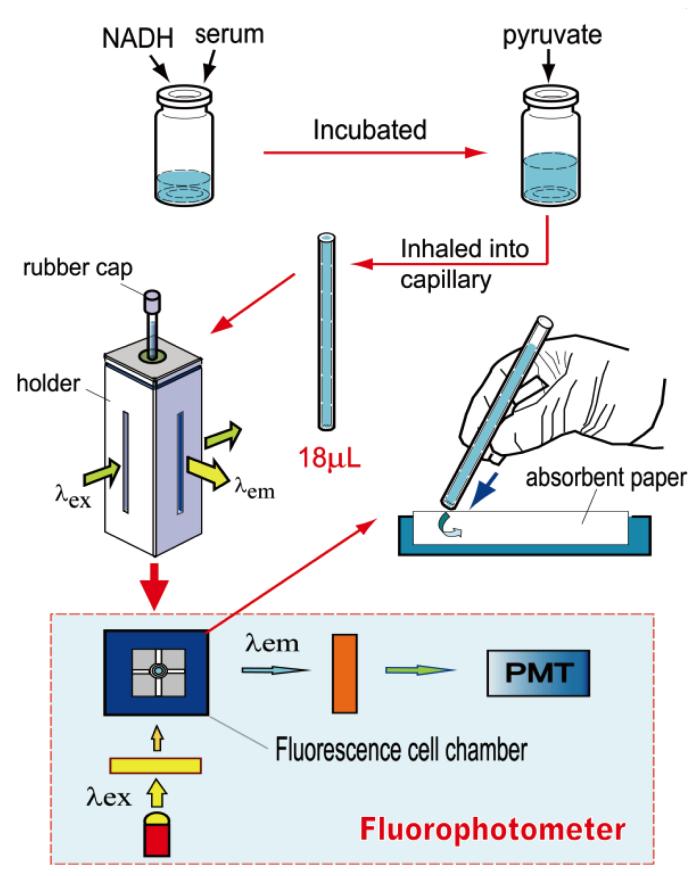

Fig. 1 Schematic diagram of the fluorescence capillary analysis (FCA).

PA concentrations, analytical range, reproducibility and detection limit, LDH recoveries in serums, and serum background.

\section{Examination of NADH standard solution stability}

Since the quenching rate of fluorescent NADH will be used for quantifying the catalytic activity of $\mathrm{LDH}$, we first examined the stability of the NADH solution $(3 \mathrm{mM})$, which was prepared with phosphate buffers having different acidity. Before testing, the NADH solutions prepared were sealed and stored in a refrigerator at $4^{\circ} \mathrm{C}$ for avoiding $\mathrm{NADH}$ oxidation in air. The obtained result (Fig. S1, Supporting Information) evinced that the fluorescent intensity of an alkaline NADH solution at $\mathrm{pH} 8.0$ can stabilize for $9 \mathrm{~h}$, while NADH solutions at $\mathrm{pH} 6.0$ and pH 7.0 demonstrated a gradually weakened trend. Therefore, the NADH solution acidity was controlled at $\mathrm{pH}$ 8.0.

Effect of phosphate buffer concentration in a pure LDH solution For investigating the effect of the phosphate buffer concentration on the stability of the pure LDH solution, phosphate buffers at different concentrations were used for the preparation of three LDH standard solutions containing $2.0 \mathrm{mM}$ PEG. The $\Delta F / \Delta t$ values of these LDH solutions were evaluated after undergoing $0.5,1.0,3.5$ and $6.5 \mathrm{~h}$, respectively. The results were that (Fig. S2, Supporting Information) when the phosphate buffer concentration was greater than $0.1 \mathrm{M}$, the $\Delta F / \Delta t$ value was no longer unchanged over time. Thus, the concentration should be chosen $0.1 \mathrm{M}$ at preparing the $\mathrm{LDH}$ standard solution.

Effect of phosphate buffer concentration in the reaction system In range $0.01-0.2 \mathrm{M}$, effect of phosphate buffer concentration (pH 6.5) was assessed concerning the $\Delta F / \Delta t$ value of NADH/ PA/LDH mixture solutions. A series of mixture solutions containing NADH, PA and LDH were prepared with different concentrations of phosphate buffers, respectively, and their 

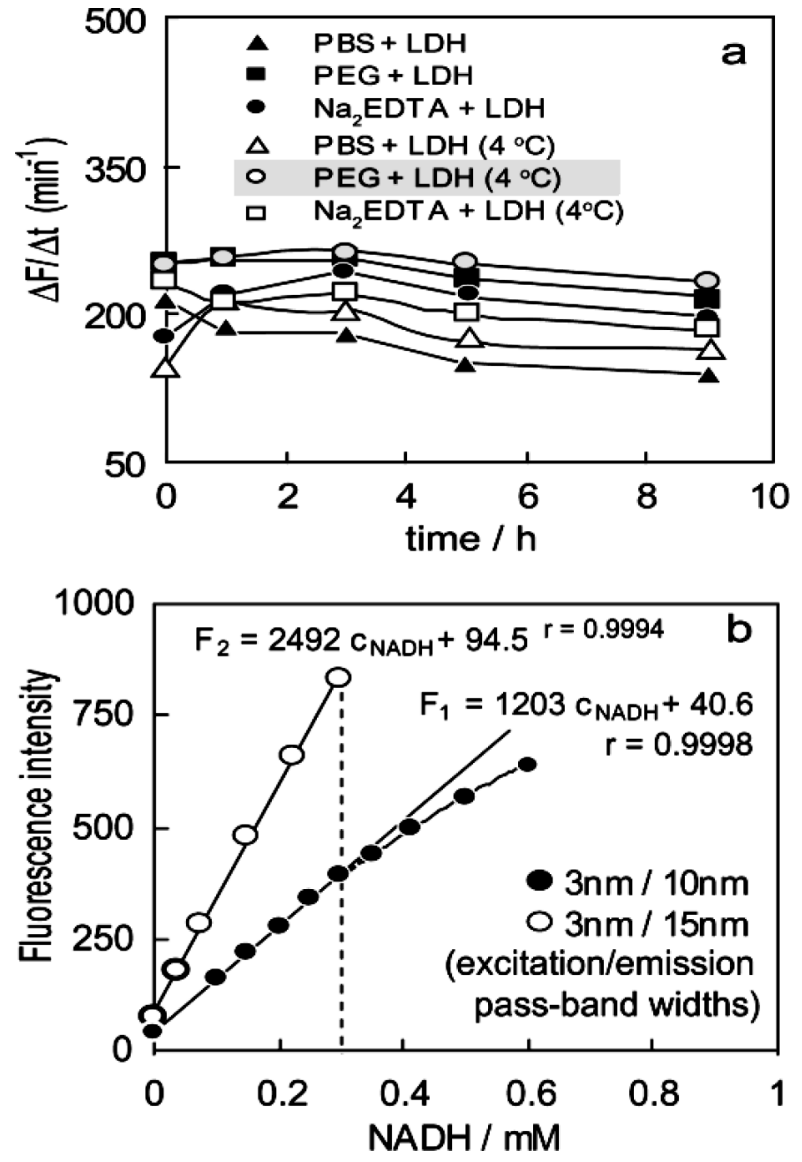

Fig. 2 Effect of different substances on LDH activity stability and correlation between the concentration and fluorescence intensity of $\mathrm{NADH}$. a. Activity changes of the LDH solution containing different substances after undergoing different times. In the figure, the LDH solution was $100 \mathrm{U} \mathrm{L}^{-1}$ prepared by PBS (pH 6.5), "PEG + LDH" contained $2 \mathrm{mM}$ PEG-6000; "Na $\mathrm{N}_{2} \mathrm{EDTA}+\mathrm{LDH}$ " contained $5 \mathrm{mM}$ $\mathrm{Na}_{2} \mathrm{EDTA} ; \mathrm{b}$. Correlation between the concentrations and the fluorescence intensities of NADH solutions at different excitation/ emission pass-band widths.

$\Delta F / \Delta t$ value was detected in sequence. The results (Fig. S3, Supporting Information) manifested that the $\Delta F / \Delta t$ value was elevated accompanying the increase of the phosphate buffer concentration in $0.01-0.1 \mathrm{M}$, and when the phosphate buffer concentration was greater than $0.1 \mathrm{M}$, the change of this value became inconspicuous. This indicates that $0.1 \mathrm{M}$ phosphate buffer was good enough for the reaction system. Therefore, the concentration was selected for the LDH catalyzed reaction.

\section{Effect of PEG on the stability of the LDH solution}

Before assaying LDH in real serum samples, we firstly examined the stability of the pure LDH solution. The obtained experimental curves (Fig. 2a) indicated whether the prepared LDH solutions were stored at room temperature or low temperature $\left(4^{\circ} \mathrm{C}\right)$, the $\Delta F / \Delta t$ values of $\mathrm{LDH}$ solutions prepared by the phosphate buffer were fluctuating. We deemed that this was due to the heterogeneity of the LDH solution. Hence, PEG solutizer and $\mathrm{Na}_{2}$ EDTA were added separately into the LDH solution to test its stability again. The results showed that $\Delta F /$ $\Delta t$ of the LDH solution containing PEG can remain stable for three hours, and this benefit was missing from that $\mathrm{LDH}$ solution added $\mathrm{Na}_{2}$ EDTA. As a result, if utilizing the calibration curve method to determine LDH activity, PEG should be added into

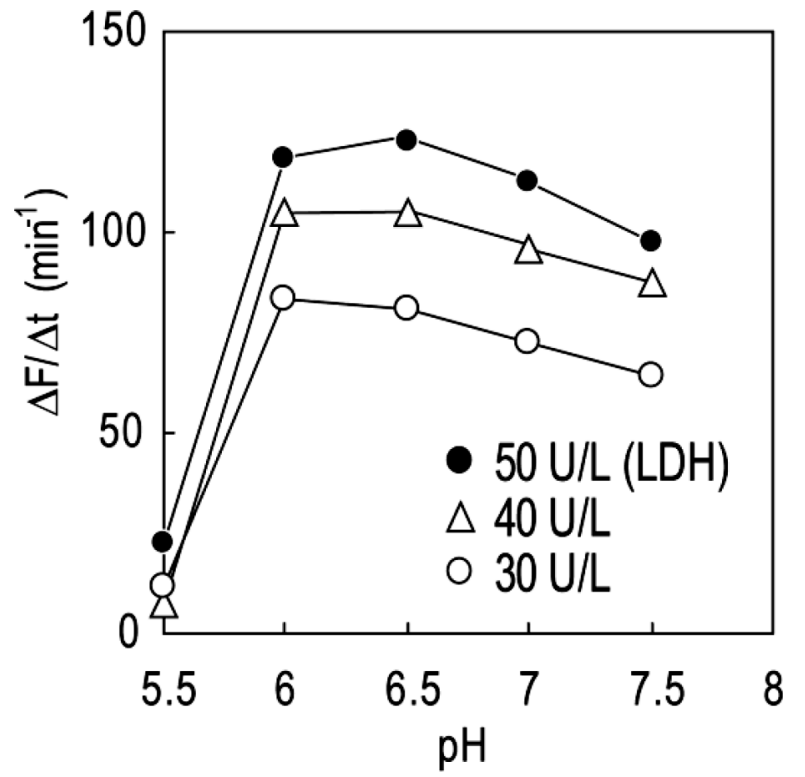

Fig. 3 Influence of the acidity on the determination of the LDH activity concentration. Each point on the curves in the figure was the mean value of thrice determining data.

\section{LDH standard solutions.}

\section{Linear response of $\mathrm{NADH}$}

After setting the pass-band widths of the excitation at $3 \mathrm{~nm}$ and the emissions, respectively, at 10 and $15 \mathrm{~nm}$, the linear correlation between $F$ and $c_{\mathrm{NADH}}$ was investigated. Two depicted plots of $F$ versus $c_{\mathrm{NADH}}$ (Fig. $2 \mathrm{~b}$ ) indicated that both the concentration and the fluorescent intensity were linearly correlated in the interval $0.05-0.30 \mathrm{mM}\left(F_{1}=1203 c_{\mathrm{NADH}}+\right.$ 40.6, $\left.r=0.9998 ; F_{2}=2492 c_{\mathrm{NADH}}+94.5, r=0.9994\right)$, and that the $K_{\mathrm{NADH}}^{(10 \mathrm{~nm})}$ value obtained by a calculation was $1203 \mathrm{~L} / \mathrm{mmol}$. The $K_{\mathrm{NADH}}^{(15 \mathrm{~nm})}$ value was $2492 \mathrm{~L} \mathrm{mmol}^{-1}$, which was almost double that of the former. As a result of the sensitivity being greater in the latter's condition, and the fluorescent intensity of $0.3 \mathrm{mM}$ $\mathrm{NADH}$ has been approached to the largest value (1000 A.U.) of the response signal scale on the fluorophotometer, thus, the follow-up tests were carried out under such conditions of $3 \mathrm{~nm} / 15 \mathrm{~nm}$ (excitation/emission).

\section{Effect of the $\mathrm{pH}$ in the reaction system}

The acidity of the reaction system affects $E_{\mathrm{C}}^{\mathrm{LDH}}$ referring to the reaction principle. Thus, the acidity of the fluorescent system was further optimized from $\mathrm{pH} 5.5$ to 7.5 under other parameters that were fixed. The test samples used were 30,40 and $50 \mathrm{U} \mathrm{L}^{-1}$ LDH standards, and the concentrations of NADH and PA substrates were 0.30 and $1.8 \mathrm{mM}$, respectively. According to the tendency of the acquired curves (Fig. 3), we can see that the maximal $\Delta F / \Delta t$ value can be obtained when the $\mathrm{pH}$ is in 6.0 6.5 range. Thus, when phosphate buffer was used as the solvent, its $\mathrm{pH}$ value should be adjusted 6.5 so as to adapt the fluorescent reaction system.

\section{Effect of the NADH concentration in the reaction system}

It can be known that the relationship of $c_{\mathrm{NADH}}$ and its fluorescent intensity is linear in the range $50-300 \mu \mathrm{M}$ (Fig. 2b). Consequently, in this range, the effect of the $c_{\mathrm{NADH}}$ variation was investigated concerning the LDH activity quantification at $2.7 \mathrm{mM}$ of $c_{\mathrm{PA}}$. The obtained experimental results (Fig. 4a) 

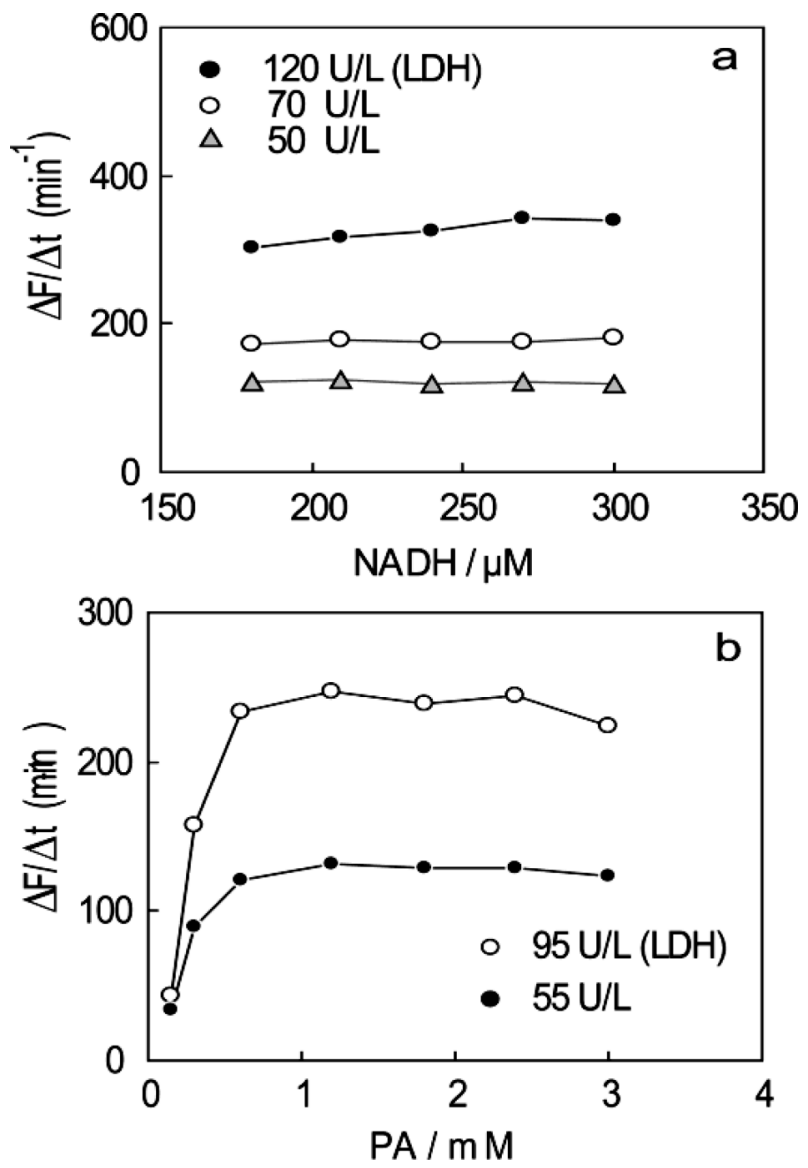

Fig. 4 Influence of the NADH and PA concentrations on the determined value of the LDH activity concentration. a. Effects of the NADH concentration; b. Effect of PA concentration. Each point on the curves in the figure was the mean value of thrice determining data.

clearly demonstrate that when the detected $E_{\mathrm{C}}^{\mathrm{LDH}}$ was higher, increasing $c_{\mathrm{NADH}}$ would slightly affect the $\Delta F / \Delta t$ value, namely would affect accuracy of the LDH activity assay. When the $E_{\mathrm{C}}^{\mathrm{LDH}}$ was lower, changing $c_{\mathrm{NADH}}$ will not affect the $\Delta F / \Delta t$ value. This phenomenon indicates that $c_{\mathrm{NADH}}$ in the reaction system should be as high as possible within its linear response interval when we determine $E_{\mathrm{C}}^{\mathrm{LDH}}$. Consequently, the $c_{\mathrm{NADH}}$ was chosen at $300 \mu \mathrm{M}$, which was the maximal value of the linear range.

\section{Effect of the PA concentration in the reaction system}

The $c_{\mathrm{NADH}}$ value was fixed at $0.3 \mathrm{mM}$, two different $\mathrm{LDH}$ standards were used as the test samples, and the effect of $c_{\mathrm{PA}}$ on the determination of $E_{\mathrm{C}}^{\mathrm{LDH}}$ was examined. From the results (Fig. 4b), we knew that $c_{\mathrm{PA}}$ observably affected the $E_{\mathrm{C}}^{\mathrm{LDH}}$ determination. The values of the $\Delta F / \Delta t$ increased with increasing in $c_{\mathrm{PA}}$ from 0.15 to $1.2 \mathrm{mM}$. However when $c_{\mathrm{PA}}$ was greater than $1.2 \mathrm{mM}, \Delta F / \Delta t$ value no longer varied with its concentration. Consequently, $c_{\mathrm{PA}}$ was chosen $1.20 \mathrm{mM}$ to the reaction system.

In summary, NADH standard solutions should be prepared using $\mathrm{pH} 8.0$ of phosphate buffer, the linear response of NADH in the $0.05-0.30 \mathrm{mM}$ range, $2.0 \mathrm{mM}$ PEG and $0.1 \mathrm{mM}$ of phosphate buffer should be added in LDH standard solutions for homogenization, the reaction mixture contains substrates of $0.30 \mathrm{mM}$ NADH and $1.2 \mathrm{mM} \mathrm{PA}$, and uses $0.1 \mathrm{mM}$ of phosphate buffer to keep its acidity of pH 6.5 .

In order to confirm the FCA advantage, under optimized
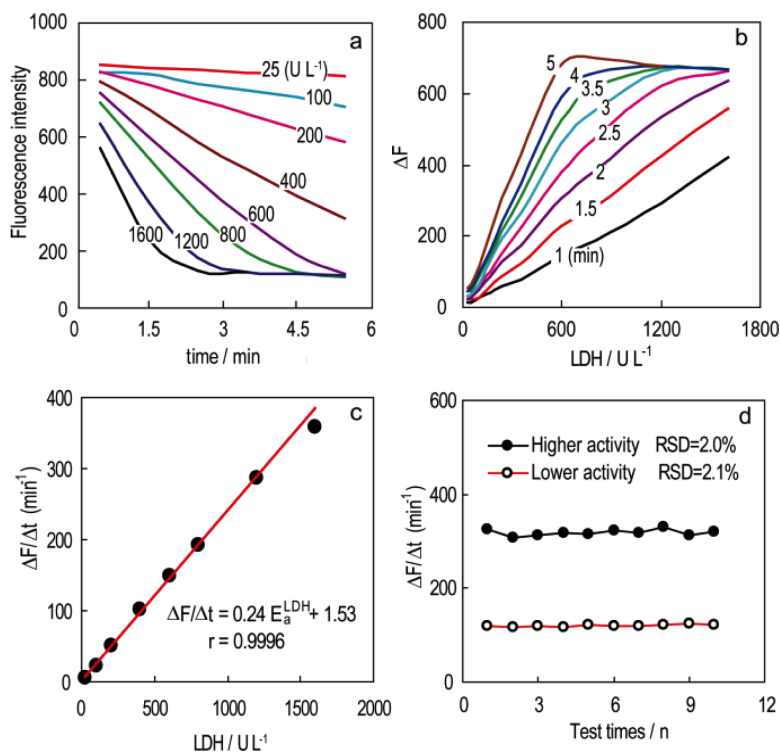

Fig. 5 Relationship between the fluorescence intensity and the activity concentration of LDH. a. Fluorescence quenching curves of reaction mixtures containing different $E_{\mathrm{C}}^{\mathrm{LDH}} ; b$. Correlation curves between the fluorescence quenching value and $E_{\mathrm{C}}^{\mathrm{LDH}}$ under different reaction times; c. Standard curves of $E_{\mathrm{C}}^{\mathrm{LDH}}$ drawn with the data within $1.5 \mathrm{~min}$ of reaction time (excitation/emission pass-band widths: $3 \mathrm{~nm} / 15 \mathrm{~nm}$ ); d. $\Delta F / \Delta t$ values obtained by repeatedly determining $E_{\mathrm{C}}^{\mathrm{LDH}}$. Each point on the curves in the figure was the mean value of thrice determining data.

conditions, an investigation was further conducted concerning the analytical range, reproducibility and detection limit of the method.

\section{Analytical range of the method}

Firstly, eight original $F-t$ curves (Fig. 5a) were obtained under different $E_{\mathrm{C}}^{\mathrm{LDH}}$ value. These $F-t$ curves indicate that the fluorescent quenching intensity decreased with increasing reaction time of the PA/NADH/LDH system, and the higher was $E_{\mathrm{C}}^{\mathrm{LDH}}$, the faster was the fluorescence quenched and the shorter was the time for complete quenching; when $E_{\mathrm{C}}^{\mathrm{LDH}}$ reached $1600 \mathrm{U} \mathrm{L}^{-1}$ in the reaction system, the fluorescence weakened quick and approached to the minimum value within $1.5 \mathrm{~min}$. This indicated that $E_{\mathrm{C}}^{\mathrm{LDH}}$ in the samples detected cannot be higher than $1600 \mathrm{U} / \mathrm{L}$ if one wishes to gain linear $F-t$ curves. Based on the relationship between $\Delta F$ and the $\mathrm{LDH}$ concentrations (Fig. 5b), it can be known that when the reaction time was fixed, the quenching amount of the fluorescence linearly heightened with the increase of $E_{\mathrm{C}}^{\mathrm{LDH}}$ in a certain range, and the longer the reaction time was, the narrower was the linear interval. Obviously, if we selected the reaction time to be very short, the linear interval of the correlation curve on $\Delta F / \Delta t v s$. $E_{\mathrm{C}}^{\mathrm{LDH}}$ would be very wide. But considering test-convenience, the reaction time should not be too short. Consequently, the reaction time was selected to be at $1.5 \mathrm{~min}$, and a calibration plot was depicted (Fig. 5c). This calibration plot showed that the linear interval of $\Delta F / \Delta t$ vs. $E_{\mathrm{C}}^{\mathrm{LDH}}$ was $50-1500 \mathrm{U} \mathrm{L}^{-1} \quad(\Delta F / \Delta t=$ $\left.0.24 E_{\mathrm{C}}^{\mathrm{LDH}}+1.53, r=0.9996\right)$. Thus, when $E_{\mathrm{C}}^{\mathrm{LDH}}$ of samples to be assay are less than $1500 \mathrm{U} \mathrm{L}^{-1}$, it can be correctly quantified by using the method.

\section{Reproducibility and detection limit of FCA-EA-LDH}

The reproducibility was tested by ten measurements using two 
Table 1 Results of LDH activity concentrations in serum samples obtained by two methods

\begin{tabular}{cccc}
\hline $\begin{array}{c}\text { Serum } \\
\text { No. }\end{array}$ & $\begin{array}{c}\text { Values obtained by } \\
\text { the method/U L }\end{array}$ & $\begin{array}{c}\text { Values obtained by } \\
\text { kit method/U L }\end{array}$ & $\begin{array}{c}\text { Correlation } \\
\text { coefficient } / r\end{array}$ \\
\hline 1 & $221.1 \pm 2.1$ & 208.0 & \\
2 & $267.3 \pm 2.3$ & 246.0 & \\
3 & $143.0 \pm 2.6$ & 129.9 & 0.9985 \\
4 & $117.2 \pm 3.8$ & 98.0 & \\
5 & $256.5 \pm 2.5$ & 237.1 & \\
\hline
\end{tabular}

different LDH standards as samples. The obtained results (Fig. 5d) indicated that the mean values and the standard deviations $(\mathrm{SD})$ of $E_{\mathrm{C}}^{\mathrm{LDH}}$ calculated by the original data, respectively, were $318.5 \pm 6.3 \mathrm{~min}^{-1}\left(1278 \pm 25.3 \mathrm{U} \mathrm{L}^{-1}\right)$ and $120.4 \pm 2.5 \mathrm{~min}^{-1}\left(483 \pm 10.2 \mathrm{U} \mathrm{L}^{-1}\right)$, and an RSD of $2 \%$ were obtained. It is thus obvious that the method's repeatability was very good. After being calculated by data of the lower LDH activity, the detection limit (3SD $k_{\mathrm{LDH}^{-1}}{ }^{-}$) was $31 \mathrm{U} \mathrm{L}^{-1}$ (3SD/ $k_{\mathrm{LDH}}=3 \times 2.5 / 0.24 ; k_{\mathrm{LDH}}$ is the slope of the LDH calibration plot (Fig. 5c) for LDH.

In summarizing, the enzyme reaction time was $1.5 \mathrm{~min}$, the quantitative range of $E_{\mathrm{C}}^{\mathrm{LDH}}$ was $50-1200 \mathrm{U} \mathrm{L}^{-1}$, RSD was $2 \%$, and the detection limit was $31 \mathrm{U} \mathrm{L}^{-1}$.

\section{Serum fluorescence background and LDH stability}

Human serum samples for quantifying $E_{\mathrm{C}}^{\mathrm{LDH}}$ were kindly supplied from some hospital of Chengdu (China). These samples were stored at $4^{\circ} \mathrm{C}$ until processing and being analyzed. ${ }^{30}$ Existing PA, enzymes or other substances in human serums might react with $\mathrm{NADH}$, which would lead to the fluorescence weakened. This would interfere with the accurate quantification of $E_{\mathrm{C}}^{\mathrm{LDH}}$. Therefore, we conducted a following experiment. Firstly, five serum samples $(20 \mu \mathrm{L}$ serum $+180 \mu \mathrm{L}$ phosphate buffer) were utilized to test their blank fluorescence, which was, respectively, $19 \pm 1.2,28 \pm 1.6,19 \pm 1.1,30 \pm 1.4$, $17 \pm 1.1$ (A.U.). It had a mean value of $23 \pm 5.3$ (A.U.). After this, the NADH reagent was added to these serum samples to see if their fluorescence changed. The results showed (Fig. S4, Supporting Information) that the fluorescent intensity of these mixtures decreased gradually over time, but they all tended to be stable after $10 \mathrm{~min}$. Thus the incubation time of the serum/ NADH mixture was set at $10 \mathrm{~min}$ so as to minimize the effect of $\mathrm{NADH}$ prequenched on posterior $E_{\mathrm{C}}^{\mathrm{LDH}}$ quantification.

Additionally, at room temperature, the stability of the serum LDH was also investigated with FCA-EA-LDH. The results showed that the LDH activity in serums collected did not vary within $12 \mathrm{~h}$.

\section{Serum LDH assay}

Under the optimized conditions and room temperature $\left(25^{\circ} \mathrm{C}\right)$, we used the method to determine $E_{\mathrm{C}}^{\mathrm{LDH}}$ in real human serum samples. Serum samples equilibrated to room temperature just before the assay. To evaluate the accuracy of the obtained $E_{\mathrm{C}}^{\mathrm{LDH}}$, it was compared with the LDH assay kit (pH 9.2, IFCC method). ${ }^{14}$ The results (Table 1) displayed that although there was a positive deviation between the determined values by our method ( $\mathrm{pH}$ 6.5) and the kit method, but their values had a positive correlation $(r=0.9985)$. The cause of forming the positive deviation should be due to the difference of the buffer acidity in the two methods.

In order to further ascertain the method's accuracy, a recovery test was, moreover, carried out. The detailed operation
Table 2 Activity recoveries of adding standard LDH into the serums

\begin{tabular}{|c|c|c|c|c|c|}
\hline $\begin{array}{l}\text { Serums } \\
\text { No. }\end{array}$ & $\begin{array}{c}\text { Initial } \\
\text { value/U L }{ }^{-1}\end{array}$ & $\begin{array}{l}\text { Added } \mathrm{LDH} \\
\text { value/ } \mathrm{U}^{-1}\end{array}$ & $\begin{array}{c}\text { Found } \\
\text { value/U L } L^{-1}\end{array}$ & $\begin{array}{l}\text { Recovered } \\
\text { value/U L } \mathrm{U}^{-1}\end{array}$ & $\begin{array}{c}\text { Recovery, } \\
\%\end{array}$ \\
\hline \multirow[t]{2}{*}{1} & \multirow[t]{2}{*}{88.1} & 185 & 270 & 182 & 98.3 \\
\hline & & 300 & 401 & 313 & 104 \\
\hline \multirow[t]{2}{*}{2} & \multirow[t]{2}{*}{109} & 185 & 301 & 192 & 104 \\
\hline & & 300 & 398 & 289 & 96.4 \\
\hline \multirow[t]{2}{*}{3} & \multirow[t]{2}{*}{105} & 185 & 289 & 184 & 99.5 \\
\hline & & 300 & 412 & 307 & 102 \\
\hline \multirow[t]{2}{*}{4} & \multirow{2}{*}{152} & 185 & 336 & 184 & 99.5 \\
\hline & & 300 & 452 & 300 & 100 \\
\hline
\end{tabular}

procedure was as follows: $5 \mu \mathrm{L}$ of $190 \mathrm{U} \mathrm{L}^{-1} \mathrm{LDH}$ standard, $20 \mu \mathrm{L}$ of the serum sample and $20 \mu \mathrm{L}$ of the NADH solution were added in one Eppendorf tube. The total volume was diluted to $140 \mu \mathrm{L}$ by using phosphate buffer; the mixture was incubated for $10 \mathrm{~min} ; 60 \mu \mathrm{L}$ of the PA solution was added into this incubated mixture and mixed quickly; and the mixed reaction solution was immediately inhaled into the capillary to test. Subsequently, 390, 580 and $770 \mathrm{U} \mathrm{L}^{-1}$ of LDH standards were added into different serum samples, respectively, and their $E_{\mathrm{C}}^{\mathrm{LDH}}$ was again determined by the above procedure. The recovery values obtained using our method (Table 2 ) were in the $96-105 \%$ range, so this clearly demonstrates the validity using our method determined $E_{\mathrm{C}}^{\mathrm{LDH}}$ in serums. But without doubt, further investigations are needed for a clinical validation of the method.

\section{Conclusions}

The method developed here can be used for quantifying $E_{\mathrm{C}}^{\mathrm{LDH}}$ in serums and can assist in clinical assays. Our approach has advantages of low consumptions $(2-\mu \mathrm{L}$ sample), low detection limit $\left(31 \mathrm{U} \mathrm{L}^{-1}\right)$, simple operations, wide linear range $(50-$ $1200 \mathrm{U} \mathrm{L}^{-1}$ ), good accuracy (recovery $96-105 \%$ ) and reliability (RSD $2.1-2.2 \%, n=10$ ), lending itself to widespread applications in the clinic laboratories and miniaturization of the fluorophotometer which transformed into a bedside instrument in hospitals. Besides, if reasonably selecting the enzyme substrate, the FCA can in principle be extended to study other enzymatic properties, and to accurately determine enzyme activities in various micro-volume samples.

\section{Acknowledgements}

The authors sincerely thank the Promotion Program Foundation of Sichuan University for the financial support of the project (No. 008204127092).

\section{Supporting Information}

This material is available free of charge on the Web at http:// www.jsac.or.jp/analsci/.

\section{References}

1. F. Wroblewski and J. S. La Due, Proc. Soc. Exp. Biol. 
Med., 1955, 90, 210.

2. C. A. Burtis, E. R. Ashwood, and D. E. Bruns, "Tietz, Textbook of clinical chemistry and molecular diagnostics", 5th ed., 2011, Saunders, Elsevier Medicine.

3. Y.-S. Li, W. Yang, Q.-J. Li, L. Zhou, and X.-F. Gao, Chin. J. Anal. Chem., 2011, 39, 1058.

4. M. Tabata, F. Koushima, and M. Totani, Anal. Chim. Acta, 1994, 298, 113.

5. H. Okuma, S. Sekimukai, M. Hoshi, K. Toyama, and E. Watanabe, Enzyme Microb. Technol., 1989, 11, 824.

6. A. Haouz, A. Geloso-Meyer, and C. Burstein, Enzyme Microb. Technol., 1994, 16, 292.

7. F. Mizutani, K. Sasaki, and Y. Shimura, Anal. Chem., 1983, 55,35 .

8. N. Minoura, S. Yamada, I. Karube, I. Kubo, and S. Suzuki, Anal. Chim. Acta, 1982, 135, 355.

9. H.-X. Ju, L. Dong, and H.-Y. Chen, Talanta, 1996, 43, 1177.

10. T. Toyoda, S. S. Kuan, and G. G. Guilbault, Anal. Lett., $\mathbf{1 9 8 5}, 18,345$.

11. C.-X. Cai, H.-X. Ju, and H.-Y. Chen, Anal. Lett., 1995, 28, 809.

12. N. Santos-Alvarez, M. J. Lobo-Castanon, A. J. MirandaOrdieres, and P. Tunon-Blanco, Anal. Chim. Acta, 2002, 457, 275.

13. R. Basi and M. Philcox, Eur. J. Clin. Chem. Clin. Biochem., 1994, 32, 639.

14. Societe Francaise de Biologie Clinique. Enzymology commission. Recommendations, Ann. Biol. Clin., 1982, 40, 87.

15. H. J. Huijgen, G. T. Sanders, R. W. Koster, J. Vreeken, and
P. M. Bossuyt, Eur. J. Clin. Chem. Clin. Biochem., 1997, 35,569

16. M. M. Nachlas, S. I. Margulies, J. D. Goldbergb, and A. M. Seligman, Anal. Biochem., 1960, 4, 317.

17. C. C. Allain, C. P. Henson, M. K. Nadel, and A. J. Knoblesdorff, Clin. Chem., 1973, 19, 22.

18. A. L. Babson and S. R. Babson, Clin. Chem., 1973, 19, 766.

19. X.-F. Gao, Y.-S. Li, and I. Karube, Anal. Chim. Acta, 2001, $443,257$.

20. J. C. Shih and E. P. Teulings, Clin. Chem., 1978, 24, 2176.

21. M. P. Nandakumar, R. Nandakumar, and B. Mattiasson, Biotechnol. Lett., 2000, 22, 1453.

22. Y.-S. Li and X.-F. Gao, Spectrosc. Spectral. Anal. (Beijing, China), 2007, 27, 1565.

23. Y.-S. Li and X.-F. Gao, Anal. Chim. Acta, 2007, 588, 140.

24. Y.-S. Li, X.-F. Gao, and Y.-X. Jiang, Chin. J. Anal. Chem., 2006, 34, S220.

25. Y.-S. Li, X. Ju, X.-F. Gao, Y.-Y. Zhao, and Y.-F. Wu, Anal. Chim. Acta, 2008, 610, 249.

26. Y.-Y. Zhao, X.-F. Gao, Y.-S. Li, X. Ju, J. Zhang, and J. Zheng, Talanta, 2008, 76, 265.

27. Y.-S. Li, W.-P. Liu, X.-F. Gao, D.-D. Chen, and W.-G. Li, Biosens. Bioelectron., 2008, 24, 538.

28. Q.-J. Li, X.-F. Gao, Y.-D. Du, T.-M. Chen, and Y.-S. Li, Chin. J. Anal. Chem., 2011, 39, 1181.

29. A. Rogers and Y. Gibon, "Enzyme Kinetics: Theory and Practice in Plant Metabolic Metworks", 2009, Springer, New York.

30. V. A. Pena, P. D. Dios, S. L. Rocamonde, R. T. Sierrac, and S. S. Rodriguez, Arch. Oral. Biol., 2004, 49, 23. 